R. Ilistúria, São Paulo, n. 129.131, p. 153-163, ago.-dez./93 a agu.-dez./94.

\title{
REPÚBLICA, IDENTIDADE NACIONAL E ANTI-SEMITISMO (1930-1945)
}

\section{Maria Luiza Tucci Carneiro*}

RESUMO: Este artigo tratn de questōes especificns ao caso clos poloneses e lus judeus imigrantes no Parantí, durante os anus 30 e 40 . Silunģes similares ocorreram em outros estudos brasileiros onde os nưcleus de colonizaçỡo europetia se fizcrann de forma marcante.

Procuramos demonstrar como que us idenis republicanos fornm minaklos pela prática de um regime nuturithrio c anti-sentita, colaborancko man levar à agonia a República brasileim.

Durantc o Estadu Novo contrariou-se o ideal de una sociedtule pduralista que abrigasse etnins Jiversificachs. $\Lambda_{p}$ efou-se. pnra o imagi nírio coletivo em busca de yuistus raciais.

PALAVRAS-CillaVE: Anti-semilismo, racismo, Paraní, poloneses, jucleus.

No decorrer do século XX e, mais especificamente, nos anos 30 e 40 , assistimos ao "desmoronar" è à agonia da República brasileira, minada em seus propósilos e tráda em seus ideais pelos profissionais do Poder. $O$ idcário republicano, calcado no lema Ordem e Progresso prestou-se, nos anos que se seguiram à proclamação, a encobrir interesses de grupos preocupados em perpetuar privilégios herdados do Scgundo Império.

Os ideais de liberdade, igualdade efraternidade cooplados do Liberalismo e da Maçonaria foram esquecidos servindo apenas de refräo aos "poderosos da República". E a República, assim como a Monarquia, tornou-se velha, rançosa, responsabilizada pelo caos e pela desordem. Adjetivos qualificativos foram acionados por aqueles que fizeram a Revolução de $\mathbf{3 0}$ instaurando a Segunda República (1930-1937) seguida do Eslado Novo (1937-1945), períodos marcados pelo autorilarismo corporificado na figura de Getúlio Dorneles Vargas.

Os ideais de liberdade, igualdade e fraternidade foram substitufdos pela disciplina do corpo e do espírito, pelo culto a força e a raça cugénica. A

Professorn Duttora do Departamento de IListória/FFLC.Il da USP. Autora dos livros $O$ anti-semitismo da Era Vargas: fantasmas de uma geraşio (Sto Paulo: Brasiliense, 1988); Preconceito rncial c'm Portugal c Brasil Colonia (Sîo Paulo: Brasiliense, 1988); O Racismo un llistória do Brnsil (São Paulo: Ática, 1994); O olhar europeu: o negro na iconografia brasileira do século XIX (Siło Paulo: Edusp, 1994), em co-autoria com Boris Kossoy. 
CARnelRo, Maria Luiza Tucci. Repúblicn, identidade nacional e anti-semilismo (1930-1945).

Jiscriminaçāo política e o preconceito racial transformaram-se em fermentos das inquietaçōes interferindo no cotidiano dos anos 30 e 40 . Instaurou-se a ditadura embutida no slogan do "nascimento de uma nova nação". O signo da Ordem continuou a ser reivindicado pelo Poder e conseguido às cuslas de repressăo policial, da contenção da massa operária e do controle do pensamento.

Seduzido pela propaganda oficial estadonovista e fascinado pelas mensagens de progresso, o povo - sem perceber - aplaudiu a agonia da Republica e saiu às ruas para venerar Getúlio, "pai dos pobres". Infelizmente, os bastidores não são transparentes.

O golpe de 1937 representou o verdadeiro repúdio ao liberalismo político e economico consumado com o fechamento do Congresso Nacional, a extinção dos partidos políticos, das eleiçōes e das garantias individuais. Outorgou-se a nova Constituição conferindo plenos. poderes ao presidente da República.

De uma forma geral, pairava no ar a idéia de que a "velha democracia liberal" estava em extinção. A Constiluiçāo de 34 passou a ser explicada como "fruto da confusão do momento histórico", enquanto que o liberalismo democrático "não se coadunava mais, de maneira alguma, com as aspirações nacionais"1.

Apesar de se negar qualquer similaridade com os regimes nazi-fascistas e ditatoriais, a realidade brasileira dos anos 30 e 40 afinava-se com os rumos trilhados pelos países europeus cujos modelos ideológicos impressionavam os governantes e intelectuais integrados ao projeto político estadonovista. Mesmo assim, diziam-se republicanos:

"Há quem tenha procurado desvirtuar a linha de conduta que traçamos, vendo na expressão Estado Novo um outro regime, senão o mesmo que mantivemos até aqui - o Republicano. Temos usado a expressão Estado Novo Brasileiro, nascida do pensamento do próprio povo - que é soberano na sua escolha para representar com ela uma época de trabalho e de reorganização social...2.

O nacionalismo alemão transformou-se em fonte de inspiraçāo do que aqui se pretendia construir: um Estado forte. Gerou também a idéia de

1 GALVÃO, F. Diretrizes do Estado Novo. Rio de Janeiro: DIP, 1942 p. 25, 26. Nota: este trabatho mereceu a mençăo honrosa no concurso de monografins institurdo pelo DIP.

2 CARRAPETA, S.G. A angústia do século XX es problemas brasileinos. Porto Alegre: Globo, 1940 , p. 126, 127. 
R. IIlsı́rìn, São Paulo, n. 129-131, p. 153-163, ago.-dez./93 a ago.-dez./94.

"perigo" - um perigo élnico - que colocava em quesıāo a proposta da formaçấo de um Estado nacional, unitormizado e padronizado culturalmente.

Estaria aqui simbolizado o ideal de igmaldade apregoado pelos positivistas desde o século passádo? Não, simplesmente. Esta uniformização cultural, étnica e unificação icleológica implicava na exclusão de grupos estranhos ao projelo de nacionalização e, lambém, de qualquer forma de contestação ao regime imposto. A hora cra de recuperaçāo dos inilos esligmatizados.

A fraternidade eslaria expressa na atitude de solidariedade aos judeus perseguidos pelo nazi-fascismo? Ao contrário, fechamos-lhes as portas endossando a política de implantação do ideal de uma raça pura, ariana.

O lipo germánico lomado como modelo para o homem brasilciro e o regime nazi-fascistä idolatrado pelos nossos dirigentes, se lornaram, subseqüenlemente, metas de homogeneização racial e praxis governamental para o Brasil; siluação delicada no momento em que os Estados Unidos cobravam o cumprimento dos "ideais democráticos". Inclusive, a polílica de repressão institucionalizada adolada pelo Brasil contra as áreas de colonização alemã (1938), sob a denúncia de infilıraçāo nazista, era contrária aos interesses da elite polftica que procurava manter um clima de indefiniçóes entre os centros hegemónicos emergentes.

Endossando, por trấs dos basstidores, a ideologia anti-semila adotada por Hitler e aplicada aos países do Reich, Getúlio Vargas encontrou uma forma de barganhar com a Alemanha, fázendo-se simpílico aos olhos dos nazistas. Com esta atitude, o governo brasileiro encontrou clima favorável para a efetivaçăo dos tratados comerciais, além de tenlar o financiamento para a construção de uma siderúrgica em atendimento aos interesses do setor industrial.

Enıre 1938 e 1939 o Brasil nāo só ampliou suas relaçōes comerciais com a Alemanha - o que preocupava muito o governo americano - como também ocorreu um estreitamento de relaçōes entre as Forças Armadas brasileiras e alemās. Ideologicamente, figuras-chaves do Ministério Vargas, como Dutra, Góes Monteiro e Filinto Müller, tendiam abertamente para o Eixo, visto que este thes oferecia mellores condiçōes de rearmamento ${ }^{3}$.

Assim, a II República agonizou diante da valorização de um Estado forte, "lutor da sociedade civil". E foi como tal yue o Poder acionou o preconceito racial contra judeus, negros e japoneses, alimentando valores adormecidos no inconsciente coletivo. Contrariou-se o ideal de uma sociedade pluralista que abrigasse etnias diversiticadas. Defendeu-se, através de atos legais, a homogeneidade racial em favor dos arianos, elementos positi-

3 GAMBINI, R. O diplo jogo de Gètuilio Vmgas: infuência americana e alemā no Estado Noiv. Siro Paulu: Sínbolo, 1977. 
CARNeIRO, Maria Luiza Tucci. República, identidade nacional e anti-semitismo (1930-1945).

vos para o configuração de uma raça forle e sadia. Combateu-se o comunismo - tratado como exótico - assim como repeliu-se o negro, o mulato, o japonês e o semita, sinonimos de impureza racial ${ }^{4}$.

Procurou-se através de decrelos-leis c circulares secretas, converler as diferenças em igualdade. Mas, não com um sentido democrático c sim racista. O termo engenia tornou-se constante nos discursos académicos e polílicos expressando ideais similares ao fascismo italiano que almejava, dentre seus objetivos, a "pureza da raça" pregada como necessária para a construçāo de uma "nova naçāo" e de um povo valorizado nos esportes.

Apelou-se para o imaginário a procura de "quistos raciais". Desafiava-se a todos e a tudo que pudesse descentralizar o regime. Sob o prisma do fenómeno emigratório, o governo Vargas delíniu-se pelo Iriunfo do homem branco, nĩo semita/não judeu. Uma política emigratória aberıa à todas as ctnias entraria $\mathrm{cm}$ conflito com o ideário político proposto pelo regime estadonovisla.

Assim, coube ao Poder fazer uma seleção arbitrária das significaçōes apresentadas à massa como necessírias, deferindo a cultura ${ }^{\mathbf{s}}$. Através da propaganda nacionalista o povo foi seduzido por mensagens legilimadoras, enquanto que à educação coube a tarefa de reforçí-las a longo prazo.

Buscava-se um modelo ideal de homem brasileiro e, diante desle impasse, É que percebemos a dificuldade que os profissionais do Poder linham em lidar com as diferençras, fossem elas étnicas ou idcológicas. O governo Vargas teve como um dos objetivos "lıomogeneizar a população". Dedicou-se a claboração - ao nível do ideal e da praxis - de um projeto educacional e de uma política emigralória em "prol do abrasilciramento da República".

Procurou-se, de todas as formas, identificar e climinar os signos de erosão da identidade cultural brasileira. E uma das primeiras iniciativas do governo foi a de inveslir contra os núcleos esırangeiros nas zonas de colonizaçāo, promulgando uma série de decrelos destinados a conter as experiências educacionais que colocassem em risco a campanha de nacionalizaçāo e construção da identidade brasileira. Por outro lado investiu-se também contra os judeus que, além de serem acusados de "esırangeiros" eram, sob vários aspectos, rotulados de "indesejáveis".

De forma repressiva e interrompendo um processo cultural de muitos anos, decretou-se o lechamento de escolas, proibiu-se o ensino em língua

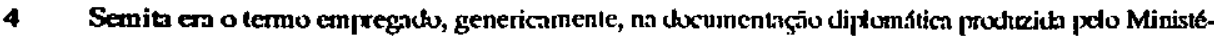
rio das Relaçies Exteriores man se referir nus judeus. Na clocumentnçâ ditn "secretn, reservadi ou cunFulencial" este tema en identificmlo cơmo "problema scmila". Subre este assunto CARNEIRO, M.L.T.

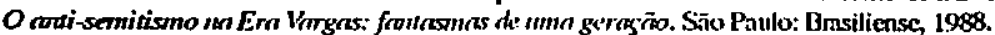

5 BORDIEU, B. e PASSERON, J.C. A reprodušño. Rio cle Janeiro: Francisco Alves, 1975, p. 20, 23. 
R. História, São Paulo, n. 129-13I, p. 153-163, ago.-dez./93 a ago.-dez./94.

estrangeira e os jornais tiveram que circular em portugues ${ }^{6}$. Esses fatos tiveram repercussão junto a imprensa dos países diretamente atingidos por esta nova política adotada pelo Brasil ${ }^{7}$, sendo que uma das maiores comunidades encontrava-se radicada no Paraná.

As primeiras iniciativas neste sentido, e que foram consideradas como "medidas rigorosas", partiram das autoridades estaduais do Paraná. No início de 1938 foram assinados decretos que proibiam, durante os três primeiros anos, o ensino de línguas estrangeiras nas escolas públicas. Nenhum estabelecimento escolar poderia ser mantido ou subsidiado pelos governos ou entidade estrangeiras. Esta determinação atingia diretamente as escolas rurais polonesas que perdiam sua razāo de ser pois o seu exercício letivo durava apenas de dois a três anos 8

Decretos semelhantes - cuja severidade cra atribuída ao chefe militar do Paraná - foram assinados em outros estados do Brasil. A Gazeta Polska, referindo-se ao caráter repressivo destes decretos, classificou-os de "fenomenos incompreensíveis do nacionalismo brasileiro":

"No Estado do Paraná, malgrado a atitude simpática do governador Manoel Ribas para com a colónia polonesa, o célebre General Vasconcelos poz-se a ditar leis como num país conquistado. Em poucos dias foram fechadas todas as associaçöes, clubs, organizaçōes sociais e escolas polonesas que nāo foram, nem na proporção de 10 por cento substituídas por outras brasileiras. A associação de cultura física ' Junak' foi dissolvida no dia 4 de maio sob a pressão de $\mathbf{3 0}$ soldados armados e de vários agentes secretos, tendo-lhes sido imposto novos estatutos, que inhibem de manter qualquer contato com a pátria de origem, tendo sido sua denominação mudada para a de 'Juventus' $n$ '.

SCHWARTZMaN, S. et alii Tempos de Capanema. São Paulo: Paz e Teria/EDUSP, 1985, p $149,152$.

7 Segundu informaçäo da Gazeta Polska existiam no Brasil em 1938, 275 poloneses, dos qais 106.000 possufam nacionalidade polonesa. O número de escolas era de $326 \mathrm{e} \mathrm{o} \mathrm{de} \mathrm{professores}$ de 352. 9.184 crianças freqüentavam escolas. Haviam 265 organizagóes calturais e agrtoclas. Havia no Brasil, 9.500 .000 crianças em idade escolar, dos quais apenas 2.100 .000 frequentavam escolas.cf. "Ameaças no regime escolar poloness no Brasit". IN: Gazeta Polska Varsbvia, I1 Lotego, 1938 .

"Passa-se mal no Brasil" IN: Express Poranny. Varsovia, 21 mai, 1938, p3. Ver tambem sobre esta queståo "O perigo de desnacionalizaçăo dos poloneses no Brasil" IN: Gaczeta Polcha. Varsobvia, 11, mai, 1938; "Unificaçăo do Brasil" IN: Correio de Varsóvia Rio de Janeiro, 21 mar. 1938.

9 "Fenômenos incompreensł́veis do nacionalismo brasileiro" IN: Gracta Polsta, 1938. 
CARNEIRO, Maria Luiza Tucci. Republica, identidade nacional c anti-semilismo (1930-1945).

Os poloneses do Paraná, acuados pela repressão policial e pela conseqüente tentaliva de desestruturação de sua identidade culturat, manifestaramse diante do elnocídio do qual eslavam sendo vítimas. Aos olhos das autoridades brasileiras, atiludes deste lipo foram rotuladas de "megalomania que, em dado momento de exacerbação, pode ter conseqüéncias sérias". Megalomania aqui Iraduzida pelo regime como sendo a "visão obsecada da Polónia de se lornar um império colonial" 10 .

O clima era de inquietação geral entre os poloneses. Em 1938 I.K.Jancewski escreveu um artigo para o jornal Kurjer Warszawski (Correio de Varsóvia) publicado em Curitiba e que mereceu comentários e transcriçóes no jornal Warsawski Dziennik Narodowy (Diario Nacional de Varsovia):

"Os nossos nervos abalados pelo rápido desenvolvimento dos acontecimentos polílicos foram levados ao auge pela publicaçāo do decreto do Interventor do Paraná, Sr. Manoel Ribas, relalivo à nacionalizaçāo das escolas...

O Eslado clo Paraná, onde existe uma colônia de 200 mil almas, está sendo dirigido por um forte governo nacionalista, do qual Laz parte uma missão especial militar, chefiada pelo inspetor Veloso e de que sāo membros o Comandante Oliveira e o Cap. Pereira. Um deles declarou que os estrangeiros que porventura dificultem a nacionalizaçāo do paíz serāo considerados como indesejáveis ${ }^{\text {"11 }}$.

A violéncia foi acionada como instrumento de domínio apoiada por uma base de poder: uma polícia política e seus informantes, alos legais, aparelho de propaganda, doutrinaçāo e censura. Como muito bem lembrou Hannah Arendt em sua obra Crises da Repiblica:

"Poder e violência, ainda que fenômenos dislintos, quase sempre aparecem juntos. A violencia é por natureza instrumental; como todos os meios, sempre necessita de orientação e justificaçĩo pelos fins que persegue... e o que necessita de ser justificado por outra crise, nāo pode ser essência de coisa alguma"12.

10 Offcio de J. de A. Figueira de Mcllo, da Legaçióo dos Esladus Unidus do Brasil em Varsóvia para Mário Pimentel Brandão, Minisıro das Relaçūes Exteriores. Varsúvia, 3 fev., 1938. In missöes Diplomóticas Brasilciras, Officios Recebidos. 1938, p.1, A.H.I.

11 "Oscalenie Brazylii" In Kurjer U'arszmiski. Dnia, 13 mar. 1938.

12 ARENDT, 11. Crises da Repuilvica. Săo Paulo: Perspectiva, 1983, p.l17, 120. Ver também, sobre este assunto: CANCELLI, E. $O$ mundo da violência: a policia da Era Vargas. Brasítia, UdUNB, 1993. 
R. Ilisıórla, São Paulo, n. 129-131, p. 153-163, ago.-dez./93 a ago.-dez./94.

Ao investir contra os poloneses, o governo investia também contra os judeus. Por volla de 1936, as autoridades diplomáticas brasileiras sediadas em Varsóvia, vasculharam - a pedido do Ministério das Relaçōes Exteriores do Brasil - a documenlaçĩo arquivada sobre a emigração polonesa para o pạís. J. Wojcikowna, auxiliar do Consulado Geral do Brasil, averiguou ficha por ficha, arrolando estatisticamente o número de emigrantes poloneses que para cá se dirigiam. Constatou que, em 1935, embarcaram 1641 emigrantes sendo 789 judeus e 90 calsos judeus agricultores. Dos 73 poloneses que cnlraram no Brasil durante o mês de junho, 63 cram judeus ${ }^{13}$.

Este número foi consiclerado como "apavorante". Clamava-se por providências que viessem a "por em terra a sophislicaria de emigrantes agricultores judeos". Na opinião de Edgardo Barbedo, diplomata brasileiro sediado em Varsóvia, as autoridades polonesas estavam facilitando documentos de "[alsos agricultores" aos judeus com a condição de que eles prometessem abandonar aquele país. Estavam envolvidas, segundo Barbedo, as companhias de colonização Terras Norte do Paraná-Inglesa e a Colônia Marques de Abrantes-Curitiba ${ }^{14}$.

Apesar de sugerir ao governo brasileiro que ficasse atento à estes mecanismos, o Cônsul Barbedo ressallou que até então lais companhias haviam fornecido gente boa e amiga do campo:

"O polonez É um elemento precioso de Irabalho, a economia nacional do Paraná e em outros Estados já lhe deve muito. Lí, entre os pinheiraes do Paraná ou perdido nas campinas das Missóes vive contente no amanho da terran ${ }^{15}$.

Entretanto, preocupado com o grande número de falsas carlas de chamada portadas pelo poloneses que se dirigiam ao Brasil - "malha por onde entra a escória judenda" - o diplomala anti-semita encerra seu ofício lembrando que:

"De tempos imemoriais é sabido que o judeu não é agricultor. Vive ele do baixo comércio, explora a miséria alheia e muilas vezes a própria"16.

13 Off́cio de Edgardo Babedo do Consulaclo Geral do Brasil em Varsóvia parn Jorge Latour, Encarregando dus Negúcios do Brạil em Varsúvia. Varsóvia, 19 out. 1936 IN: missōes Diplomónicas Brrasileiras, Oficios Recebidos, out. 36 a 37, p.3 A.H.I.

$14 I d c m$, p. 3.

15 Idem.

16 Idem, p.4. 
CARNEIRO, Maria Luiza Tucci. República, identidade nacional e anli-semilismo (1930-1945).

Devemos considerar que, por Irás desıas manifeslaçōes de anti-semilismo de parte da diplomacia brasileira e do processo de nacionalizaçíio, estava a apreensão do governo com as atitudes ditas "expansionistas" da Polónia considerada como uma grande potencia c con atiludes de país imperialisia ${ }^{17}$.

Segundo Jorge Latour, o governo polonẻs procurava encobrir suas verdadeiras intençōes tentando fazer a compra de latifúndios no Brạsil acobertando o governo, real proprielírio, com o nome de sociedades ou sindicatos aparentemente privados. Da mesma forma promovia, segundo o referido diplomata Lalour, a criaçāo de "sociedades de intuitos ilusoriamente confraternizadores, com publicaçōes e méludos de propaganda divina". Como evidencia desta realidade cita a Sociedade Polono-Brasileira "Koszinsko" que mantinha frliais em Curiliba e Porto Alegre.

Acredilava-se que através de um acurado "plano de colonizaçĩo dirigida e localizada", o governo da Polonja estava incremenlando, cada vez mais, a "polonização" do filho do polones nascido no Brasil através de uma imprensa própria que, nos esiados sulinos, circulavam em idioma polones.

Outro alerta foi contra a criação e a subvenção de escolas primárias em lerritórios da República brasileira facilíada pela "vigilancia deficiente e precária das autoridades do ensino no interior do país". Segundo nosso Encarregado de Negócios, Jorge Lalour, o governo polonês através do Sindicato de Emigraçāo e do Ministério de Assisténcia Social (aos quais correspondia uma secção de emigração do Ministério dos Negócios Estrangeiros) tentava dificultar, por todos os modos, o contrato de imigrantes destinados à outros cśtados que nāo fossem Rio Grande do Sul e Paraná onde possuíam vaslas terras com tílulo regular de propriedade.

Uma das possibilidades alegadas é que o Paraná eslivesse servindo de "ponte" para outros núcleos de colonização sistemática já formados na Argentina e Paraguai. Portanto, com tantos argumentos, nada mais lógico do que a tentativa do governo brasileiro de minar, por todos os lados possíveis, a comunidade polonesa instalada no sul do país.

Uma outra razāo apresentada como prova das intençöes imperialistas da Polónia no Paraná foi a inscriçấo dos estatutos da "Uniño Central dos Poloneses no Brasil" no livro de Registro de Sociedades de Curitiba. Segundo as autoridades diplomálicas, esta entidade - valendo-se do que dispunha o artigo 18 do Codigo Civil, sobre sociedades de fins civis - "gozava de favores excepcionais

17 Offeio de Jorge Latour parn Mario Pimentel Brandio, Ministro de Estndo Interino das Relnģues Exteriores, out. 36 a 37. A.H.I. 
R. IItstórta, São Paulo, n. 129-131, p. 153-163, ago.+dez./93 a ago.-dez./94.

e com elles encobrindo actividades cujo alcance c conseqüências exatas eram. difíceis de ayuilalar"18. Eslat sociedade, "secrelamente subvencionada pelo governo polonês com verbas criadas para o cxpansionismo", na realidade teria "fins polílicos e álenlallórios à̀ soberania nacional" ${ }^{19}$.

A versão oficial era a de que alravés desta sociedade conseguia-se burlar a lei de emigração vigenle (Arl. $8^{\circ}$, lełra e, e do Decreto n²4.259 de 16.05.1934), possibilitando alos poloneses - enläo "esırangeiros-indesejáveis" - de entrarem em lerritório nacional para fins de ensino; fato que os isenlav: la exigência de apresentarem carlas de chamada.

Lista lorma, inumeros poloneses sob o título de "professores" teriam sido "convidados" pela relerida sociedade que the arbilrava um ordenado. Aparentemente estariam sendo contratados parn servir em escolas polonobrasileiras no Brasil. O cônsul Edgardo Barbedo chegou a documentar lais acusaçöes com o objelivo de comprovar a plasticidade e o sub-reptício dos métodos empregados pelo chamado "imperialismo polaco". Neste caso estariam envolvidos os seguintes "professores":

- Tadeuza Borkowski, de Escola de Sanla Calarina (convite n 1.135)

- Tadeu Wosniak, da Escola Polono-brasilcira de Cruz Machado-PR (convite $\left.n^{2} 1.137\right)$

- Tadeu Murawsky, do Colégio Nicoláo Copérnico, em Marechal Mallet-PR (convite $\left.\mathrm{n}^{\circ} 1.139\right)$

- Luiz Lawski, do Colégio Henrique Sienkie, de Curitiba-PR (convite $\left.{ }^{\circ} 1.139\right)^{20}$.

Nem mesmo o Consulado Geral da Polónia, sediado am Curitiba, escapou desta forma sutil de acusações, mescladas por um exacerbado nacionalismo: aquele órgão dispunha "de mais de 25 funcionários de quadro, fora os residentes por ele contratados". Na opinião de Barbedo, o governo brasileiro deveria manter vigiláncia melódica com o objetivo de conter o "expansionismo" polonês no Sul do Brasil e, por outro lado, impedir a entrada de judeus, acusados de serem "falsos agricultores".

18 Ver Livro n" 2 w Registro de Sociedades de Curitiba, N' 41, 28 abr. 19 IN: Mtissöes Diplomáticas Bmsileiras, Oficios Recebidos, out. 36 a 37, p. 3 A.H.I.

19 Idem, p. 3.

$20 \quad 1 d e m, p 4$. 
CARNEIRO, Matia Luiza Tucci. República, idenlidade nacional e anti-semitismo (1930-1945).

Esle estado de alerı - traduzido pela polílica de nacionalização c pela aplicação de uma política anti-semita - ocasionou atitudes de resistência. É comum, no momentos de aceleraçăo da história, o apego ao passado, à língua materna e às Iradiçōes religiosas como forma de resistência e de preservação da identidade cultural; mesmo quando o grupo é́nico já se adaplou à realidade brasileira e seus representantes já se encontram na segunda ou terceira geraçĩo. Muitos Jos "poloneses", "alemães" e "ilalianos", alingidos pela política de nacionalizaçāo adotada por Vargas, já eram brasilciros natos. No entanto, carregavam o esligma de serem filhos de imigrantes c/ou neto de judeu.

Todas estas questóes comparlilhavam do projeto polílico proposto pelo regime estadonovista que recolocou em cena o nacionalismo, unindo o pensamento dos governantes e dos intelecluais como uma nova resposta à crise do mundo liberal ${ }^{21}$. Este misticismo que envolveu o novo regime, após 1937, era decorrente da idcologia do nacionalismo burguês caracterizado pela construção do Esıda Nacional.

Este não foi um caso específico do Brasil, mas um modelo importado da Europa onde a Alemanha e Itália já colhiam suas glórias de "nação forte". Só que estes movimentos nacionalistas eram de cunho "separatistas", daí a insistência na eliminação das diferenças élnicas e lingüísticas. Neste caso percebemos uma clara distinçĩo com "alguns clos mais antigos e inquestioníveis Estados-Naçōes onde não se chegou a negar", segundo Eric Hobsbawn, a real "multinacionalidade ou a multilingualidade ou multielnicidade" como aconteceu na Grā-Brelanha, França ou Espanha ${ }^{22}$.

Apresentava-se como imperalivo a formaçāo de uma raça homogênea, de um povo integral adaptado à realidade social de seu país e preparado para servi-lo. Essas propostas polílicas - um fim a ser urgentemente atingido Coram marcadas por duas diretrizes tendo em conta a alegada gravidade daquele momento histórico:

- a proteção ao homem brasileiro;

- o progresso material e moral do país.

Assim, a assimilaçĩo das minorias étnicas, lingüísticas e culturais que haviam se inslalado no Brasil descle as últimas décadas, transformaram-se em questão de segurança nacional, ameaçando a ordem social c a formaçāo da consciéncia patriótica brasileira. Neste contexto, o judeu imigrante se pres-

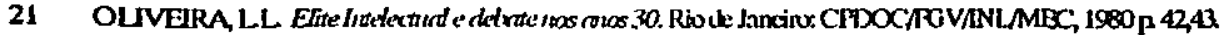

22 HOSBSBAWN, E. J. Naşöes e nacionalismos deste 1780; Traduçío Maria Célia Paoli e Ana Maria Quirino. Rio de Janeiro: Paz, e Jern, 1990, p. 45. 
R. Histórla, Såo Paulo, n. 129-131, p. 153-163, ago.-dez./93 a ago.-dez./94.

tou à figura do "estranho sem pátria", carregando consigo uma forte estigmatizaçāo político-ideológica; argumento que compunha as justificativas da proposta de nacionalização enfatizadas pelo governo.

Apesar das proibições e do clima de tensāo gerenciado pelas autoridades diplomáticas brasileiras, os judeus foram chegando, silenciosamente. Adequaramse ao cotidiano brasileiro sem encontrar explicações para o livre trânsito que os nazistas alemães tinham pelos núcleos de colonização sediados no sul do país.

As circulares secretas que entraram em vigor contra o imigrante judeu a partir de 1937, a correspondéncia anti-semita que circulou por entre os ministérios e missões diplomáticas brasileiras, a publicaçāo de obras integralistas e católicas de caráter anti-judaico e os discursos em prol da configuração de uma raça ariana pura, nos comprovam que a República Varguista não teve a sensibilidade - e nem estava preocupada com isto - para entender o "outro".

A desativaçăo dos sistemas educacionais implantados pelas comunidades alemãs, polonesas e italianas radicadas no Brasil, a proibição do uso da língua de origem e a prisāo daqueles que foram identificados como judeus/comunistas, simbolizou o suicídio simbólico de várias etnias que, por si só, criaram alternativas de resistência.

Cabe ressaltar que o imigrante ou o filho de imigrante que perde sua estrutura lingüística e cultural; o judeu que tem suas tradições religiosas interrompidas, torna-se um "homem mutilado". A memória coletiva se faz pelo acúmulo permanente das Iradiçōes edificadas a partir de experiências dos mais velhos, sejam eles nacionais ou estrangeiros. Um patrimônio cultural se constrói pela criaçāo de um passado comum, onde raça e religião não devem constar como critérios de seleção e a violência não deve persistir como instrumento legal.

A cullura não se constrói e nem se edifica uma nova - dita autêntica, nacional - através da destruiçāo de outras. As raízes sāo sempre significativas, simbolicamente falando. Felizmente estas comunidades - alemãs, italianas, polonesas e judaicas - resistiram e hoje são partes integrantes da naçāo brasileira - um mosaico de etnias.

ABSTRACT:' This article deals with specific issues relating to Polish and Jewish immigrants in Parana Juring the 1930s/40s. Similar situations took place in other Brazilian states where Europenn colonization nuclei were established.

The Republican ideals were shattered by an authoritarian and anti-semitic regime during the $E$ s. tado-Novo. This lead to the distress of the Brazilian Republic and was contrary to the ideal of a pluralist society which would embrace diverse ethnic groups. There was an appeal to the collective imaginary in search of racial clusters.

KEY-WORDS: antisemitism, racism, Paraná, Poles, Jews. 